\title{
Article \\ Fenton-Chemistry-Based Oxidative Modification of Proteins Reflects Their Conformation
}

\author{
Thomas Nehls ${ }^{\dagger}$, Tim Heymann ${ }^{\dagger}$, Christian Meyners $\mathbb{D}$, Felix Hausch and Frederik Lermyte *(1) \\ Clemens-Schöpf-Institute, Department of Chemistry, Technical University of Darmstadt, Alarich-Weiss-Straße 4, \\ 64287 Darmstadt, Germany; thomas.nehls@tu-darmstadt.de (T.N.); tim.heymann@tu-darmstadt.de (T.H.); \\ christian_stephan.meyners@tu-darmstadt.de (C.M.); felix.hausch@tu-darmstadt.de (F.H.) \\ * Correspondence: frederik.lermyte@tu-darmstadt.de \\ † These authors contributed equally to this work.
}

check for

updates

Citation: Nehls, T.; Heymann, T.; Meyners, C.; Hausch, F.; Lermyte, F. Fenton-Chemistry-Based Oxidative Modification of Proteins Reflects Their Conformation. Int. J. Mol. Sci. 2021, 22, 9927. https://doi.org/ $10.3390 /$ ijms 22189927

Academic Editors: Istvan Simon and Csaba Magyar

Received: 8 August 2021

Accepted: 11 September 2021

Published: 14 September 2021

Publisher's Note: MDPI stays neutral with regard to jurisdictional claims in published maps and institutional affiliations.

Copyright: (c) 2021 by the authors. Licensee MDPI, Basel, Switzerland. This article is an open access article distributed under the terms and conditions of the Creative Commons Attribution (CC BY) license (https:// creativecommons.org/licenses/by/ $4.0 /)$.

\begin{abstract}
In order to understand protein structure to a sufficient extent for, e.g., drug discovery, no single technique can provide satisfactory information on both the lowest-energy conformation and on dynamic changes over time (the 'four-dimensional' protein structure). Instead, a combination of complementary techniques is required. Mass spectrometry methods have shown promise in addressing protein dynamics, but often rely on the use of high-end commercial or custom instruments. Here, we apply well-established chemistry to conformation-sensitive oxidative protein labelling on a timescale of a few seconds, followed by analysis through a routine protein analysis workflow. For a set of model proteins, we show that site selectivity of labelling can indeed be rationalised in terms of known structural information, and that conformational changes induced by ligand binding are reflected in the modification pattern. In addition to conventional bottom-up analysis, further insights are obtained from intact mass measurement and native mass spectrometry. We believe that this method will provide a valuable and robust addition to the 'toolbox' of mass spectrometry researchers studying higher-order protein structure.
\end{abstract}

Keywords: mass spectrometry; protein folding; protein-ligand interactions; protein dynamics; FK506-binding protein; FKBP12; FKBP51

\section{Introduction}

Protein structure is inherently a four-dimensional phenomenon, and the dynamic aspects of a protein can be just as important as the mostly static structures typically associated with conventional high-resolution structural biology methods, such as X-ray crystallography. In recent years, gas-phase methods, such as native mass spectrometry and ion mobility spectrometry, have been developed that lack the high resolution of crystallography, nuclear magnetic resonance, or cryo-electron microscopy, but can complement these methods such that the combination of different techniques yields a better understanding of the structural ensemble [1-7]. A benefit of MS-based methods is their near-universal applicability and relatively high throughput. While it is now generally accepted that the gas-phase structure of proteins in native MS reflects important aspects of the solution structure, the question remains to what extent subtle interactions are preserved [3].

One way to combine the analytical benefits of mass spectrometry with the ability to confidently probe protein structure as it appears in solution is to use chemical labelling [8-10]. This can be performed in a way that is sensitive to protein conformation in solution, and subsequent MS analysis allows identification of the modification sites, which facilitates correlation of primary and higher-order structure. Such methods provide valuable complementary information to conventional structural biology, for example, allowing the convenient probing of membrane proteins, or monitoring the response to a thermal or chemical perturbation of the structure on a (sub)millisecond timescale [11-15]. These 
methods also have the benefit that their experimental feasibility typically only has a limited dependence on protein mass [16].

Arguably, the most common labelling method in use today is hydrogen-deuterium exchange (HDX), which allows modification of backbone amide groups in a way that is sensitive to both solvent accessibility and hydrogen bonding, i.e., secondary structure [17-20]. While this is a powerful method, the kinetics of the exchange reaction are highly sensitive to experimental factors, such as temperature and $\mathrm{pH}$, and, therefore, considerable expertise is required for a successful HDX experiment, which, as a result, is still hardly a routine approach. Furthermore, analysis is typically performed with enzymatic digestion at low $\mathrm{pH}$ and temperature, followed by chromatographic separation and MS analysis of peptides. Due to the reversible nature of the labelling reaction, there is always a degree of back-exchange during this step of the experiment, and this has to be carefully controlled. For this reason, the best results are often obtained using automated sample preparation and handling, which allows better precision and accuracy than human-level control over the experiment. Finally, due to the mobilisation of protons (or deuterons) in gas-phase peptides under high-energy conditions, the most common fragmentation technique in mass spectrometry-collision-induced dissociation-causes randomisation ('scrambling') of labelling sites, which limits the resolution of the method to the peptide level [21,22].

For these reasons, irreversible covalent labelling in MS-based structural biology can offer valuable additional information. Different chemistries have been used for this over the years, ranging from conventional substitutions to radical chemistry, for example, with carbenes [10,23-25]. Great strides have been made in the use of hydroxyl radicals for footprinting after homolytic dissociation of hydrogen peroxide upon ultraviolet irradiation, typically employing an excimer laser. This method is known as fast photochemical oxidation of proteins (FPOP) [26-28]. Due to the very short lifetime of the radicals (particularly as a scavenger is typically added to the solution) it is possible to probe the evolution of protein structure on a microsecond timescale, although it should be noted that Vahidi and Konermann have shown evidence that it can take up to milliseconds for all metastable secondary radicals to be destroyed [29]. The use of hydroxyl radicals is particularly attractive, as they are essentially the same size as water molecules and labelling, therefore, captures the biologically relevant solvent-accessible surface. Before the development of FPOP, Chance and colleagues demonstrated the use of synchrotron radiation to form hydroxyl radicals from water, also leading to selective labelling of the exposed surface of a protein [30,31]. While powerful, these methods rely on access to very specialised equipment and, as such, are out of reach for most researchers. Therefore, there is a need for robust conformation-sensitive labelling approaches that can be easily implemented in more routine settings.

Hydroxyl radicals can of course be conveniently produced in solution in a number of ways, most famously by Fenton chemistry. In this case, hydroxyl radicals are produced by reaction of hydrogen peroxide with $\mathrm{Fe}(\mathrm{II})$, yielding $\mathrm{Fe}(\mathrm{III}), \mathrm{OH}^{-}$, and $\mathrm{OH}^{\bullet}$, the latter of which can react with amino acid side chains. For a residue-specific overview of possible modifications, we refer the reader to the excellent recent review by Gross and colleagues [10]. Pioneering work by Tullius and Dombrowski demonstrated the use of an elegant Fenton system for probing protein-DNA interactions [32]. In this work, radical production was achieved by a redox cycle involving Fe(II)-EDTA, hydrogen peroxide, and ascorbate to regenerate the Fe(II). Attack by the hydroxyl radical then led to cleavage of exposed parts of the DNA backbone. Subsequent analysis of DNA fragments was performed by gel electrophoresis; however, possible modifications to the protein interaction partner were largely ignored. Interestingly, despite continued use of Fenton chemistry for characterising the structure of nucleic acids bound to protein, there has been limited interest in its use for oxidative footprinting of proteins compared to radiolysis [10,33-36]. Several reasons have been reported for this; for example, (i) the Fenton reaction cannot be initiated and quenched on the same timescale as FPOP; (ii) there is the risk that iron, EDTA, or other components in solution might interact with the protein of interest and induce a 
conformational change; and (iii) letting the process continue for too long could permit undesired secondary reactions [37].

Despite these concerns, here we explored whether Fenton chemistry can be combined with routine proteomics sample preparation and LC-MS to reveal insight into protein structure and dynamics. The overall workflow is represented schematically in Figure 1. Using a set of model proteins with masses between 10 and $150 \mathrm{kDa}$, we found that we were indeed able to selectively label the exposed protein surface. For the FK1 domain of the immunophilin FKBP51-currently an important drug target due to its relevance in mood disorders $[38,39]$ - differences in the modification pattern between the ligand-free and -bound form were consistent with the known binding site of two different ligands, based on crystallography [40,41]. We were able to apply the same method to complexes of the homologue FKBP12 without any particular difficulty. Finally, in the case of myoglobin, we unexpectedly found that the iron centre in the noncovalently bound haem group was also able to participate in the Fenton reaction. As a result, oxidative footprinting for this protein reflected not only surface exposure in a way consistent with the known structure and labelling experiments from the FPOP literature, but also reflected the binding mode of oxygen to this prosthetic group.
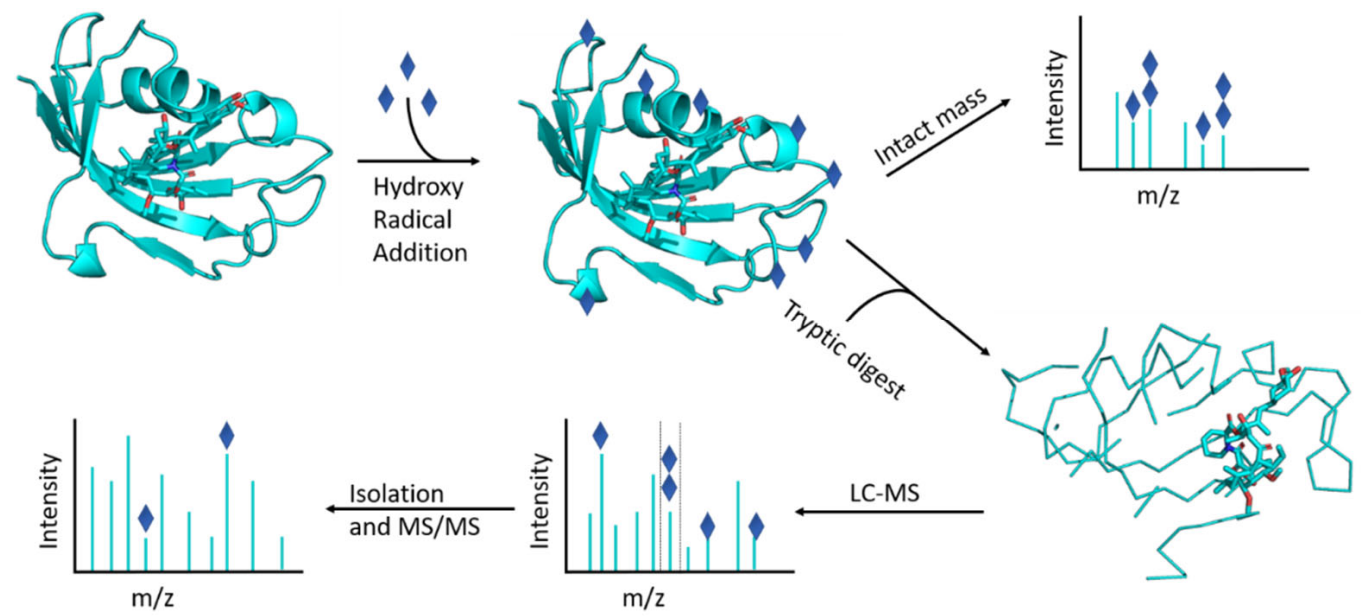

Figure 1. Schematic representation of the oxidative footprinting workflow.

\section{Results}

We used four model proteins to benchmark our method in this study: one large, noncovalent complex in which sequence regions involved in protein-protein binding interfaces constitute a clearly defined protected 'core', a smaller protein with a noncovalent haem group, and two small drug targets. Interestingly, each of these model systems highlighted a different aspect of the use of Fenton chemistry for oxidative footprinting, and the presentation of the results is, therefore, organised by protein substrate.

\subsection{Myoglobin: Intrinsic Fenton Reactivity Reflects Co-Ordination Mode of the Haem Group}

As a first model system, we decided to use myoglobin, as this $17.6 \mathrm{kDa}$ protein (including a haem group with a mass of $616 \mathrm{Da}$ ) has been well characterised by various techniques, including several reports in the early FPOP literature [26,27]. As such, we were eager to determine how the oxidation pattern in Fenton-chemistry-based footprinting would compare to those published results. Furthermore, it is well known that loss of the prosthetic haem group causes significant structural destabilisation in this protein, especially in the C-terminal half of the sequence (helices F, G, and H) [26,27,42]. Therefore, we anticipated that comparing results for holo- and apo-myoglobin would provide a clue about the ability of our method to distinguish between different conformational states. After quenching the footprinting reaction, an aliquot was taken for intact mass measurement, which was performed under denaturing conditions. Results are shown in Figure 2. In agreement with 
the FPOP literature, a fairly similar overall level of oxidation was observed for apo- and holo-myoglobin, with the latter appearing slightly more oxidation-sensitive [26,27].

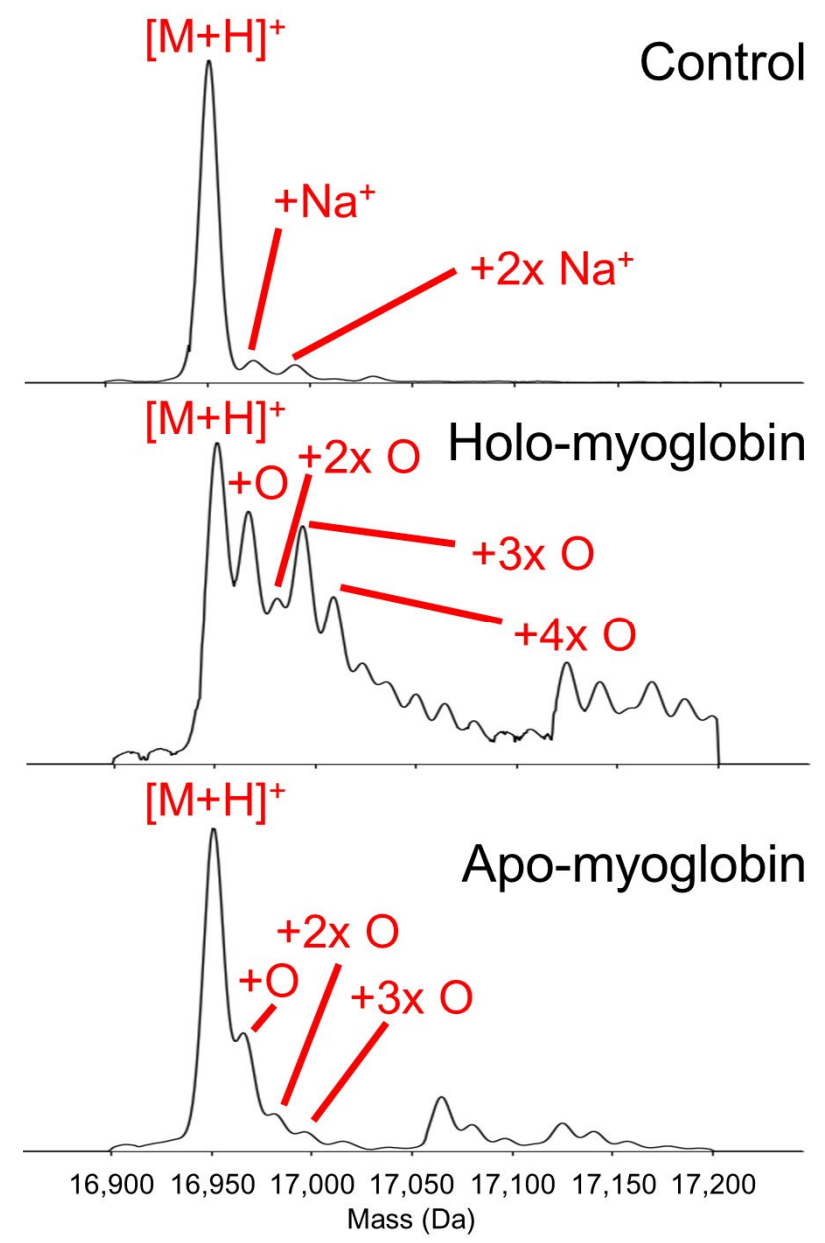

Figure 2. Deconvoluted mass spectra of apo-myoglobin and holo-myoglobin before ('control' experiment in the top panel) or after oxidative footprinting. Oxidative footprinting was carried out under native-like conditions, but samples were chemically denatured prior to MS measurement, which is why the haem group is not retained in holo-myoglobin. Only one spectrum is shown in the top panel as apo- and holo-myoglobin are identical after chemical denaturation.

Subsequently, oxidation site determination was performed through bottom-up analysis, where differences between both states of the protein were observed. Overall, our data were consistent with those in the early FPOP work, where a good agreement with the exposed surface was already established based on the known crystal structure (see Figure 3) [26,27]. Importantly, as described by Gross and colleagues, His93, which directly co-ordinates the iron centre in the haem group, was efficiently oxidised in apo-myoglobin, but was protected from oxidation in holo-myoglobin [27]. The main discrepancy between our results and those in previous reports was significant oxidation in holo-myoglobin of residues Leu32, Lys42, Phe43, Val68, Leu72, Ile99, Tyr103, and Phe138 in the binding pocket of the haem group (coloured orange in Figure 3). Note that, as described in Materials and Methods, oxidised residues were identified using tandem MS - for example, fragments $b_{10}$, $b_{11}, y_{4}$, and $y_{6}$ from the oxidised peptide L(32)FTGHPETLEKFDK(45) bracketed the Lys42 and Phe 43 residues, allowing us to say that these were both oxidised, rather than the mass shift being a result of, for example, double oxidation of phenylalanine. 


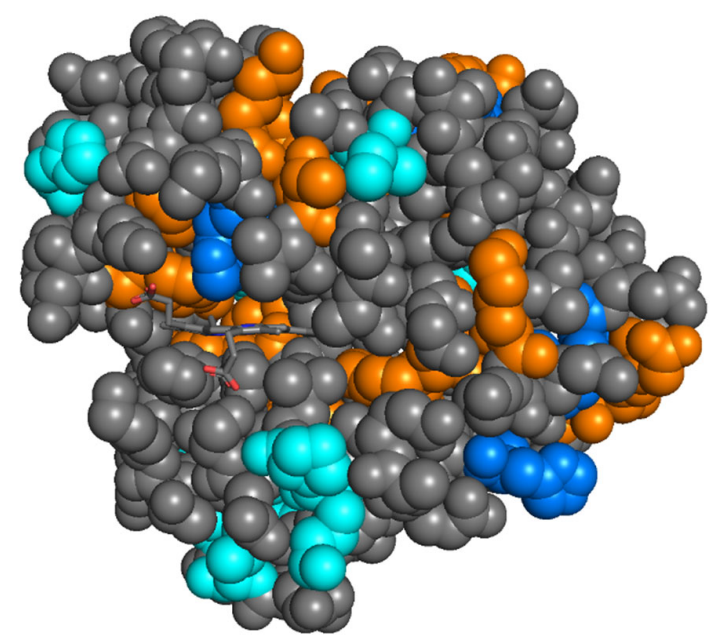

Figure 3. Crystal structure of holo-myoglobin (Protein Data Bank accession code 1YMB), with important residues for oxidative footprinting highlighted. Residues that were oxidised in our work that were previously identified as oxidation-sensitive in the FPOP literature are coloured blue. New modifications identified in our work (mostly near the haem group) are coloured orange. Modification sites that were identified in the FPOP literature but not in our experiments are coloured cyan.

As we used the same commercial supplier as Gross and colleagues, and the control experiment shown in Figure 2 confirmed the molecular mass and lack of modifications, we assumed the aforementioned discrepancy was due to a difference in reaction conditions rather than a difference in protein structure. Given the different method for generating hydroxyl radicals (flash photolysis vs. Fe/ascorbate-driven redox chemistry), we hypothesised that the iron centre within the haem group was involved in Fenton-like redox cycling in the presence of ascorbate, and that radicals were generated in close proximity to the haem group in this process. To test this, we repeated the experiment, but did not add any extrinsic iron in the form of Fe(II)-EDTA to the reaction mixture (i.e., only ascorbate and hydrogen peroxide). As before, the reaction was quenched after $15 \mathrm{~s}$.

Under these conditions, we observed very little oxidation at surface regions remote from the haem group, while residues near this group were, again, oxidised extensively, in good agreement with our hypothesis. Interestingly, His93 and other residues on its side of the plane of the haem group were largely protected, and oxidation was mainly observed in residues located on the opposite side in the native structure, including His64, which also co-ordinates the iron centre. This opposite side is where oxygen binds to iron, displacing His64 in the process (see Figure 4); hence, this oxidation pattern seems to reflect the increased local conformational flexibility and space required to allow the protein to perform its oxygen transport function in vivo. Metal-catalysed oxidation of amino acid residues in the vicinity of biologically relevant metal ions has been observed before [43]; however, here, the oxidation pattern not only provided information about the binding region, but also reflected the solution-phase dynamics of ligand binding to and release from the metal. 


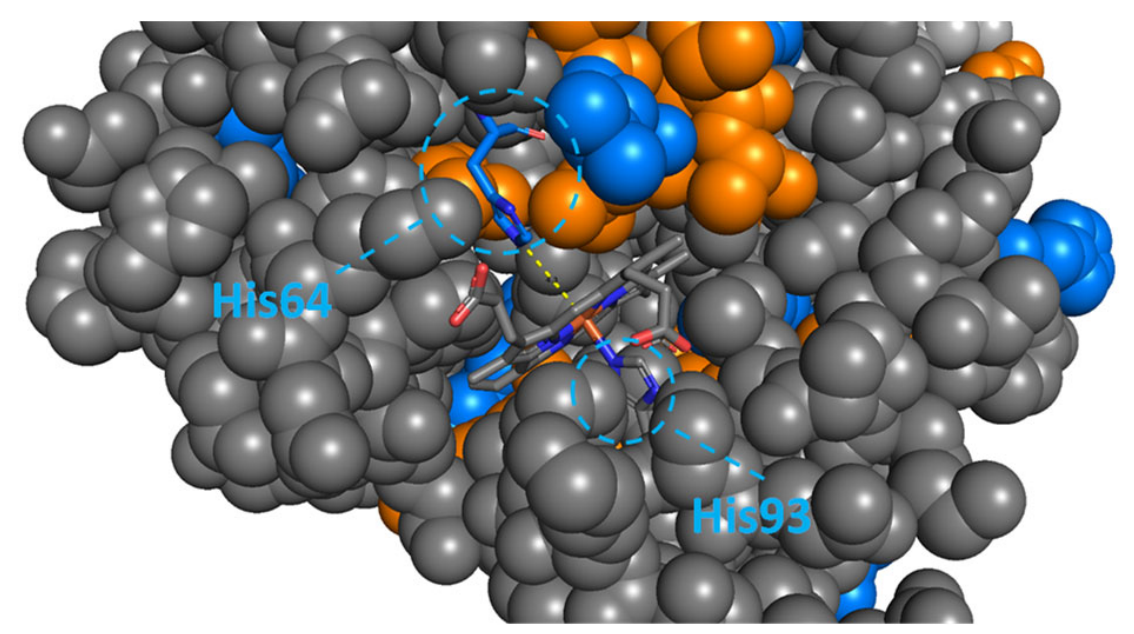

Figure 4. Crystal structure of holo-myoglobin, focussed on the binding pocket of the haem group. Highlighted residues were oxidised in the presence of ascorbic acid and hydrogen peroxide, without addition of Fe(II-EDTA. Residues in blue were identified in two independent ways with MaxQuant (either through fragmentation of two overlapping peptides, or from two different oxidative chemical modifications in the same peptide) [44,45]; those in orange were detected once (see Section 4 for details).

\subsection{ADH: Highly Reactive Sulphur-Containing Side Chains and Surface-Selective Labelling}

While our results for myoglobin-including the redox activity of the haem groupwere intriguing, we wanted to further investigate the ability of our Fenton-chemistry-based method to selectively modify the solvent-exposed surface of a protein. For this reason, we wanted to use a model system without any redox-active metals. We selected alcohol dehydrogenase (ADH), which forms a $148 \mathrm{kDa}$ tetramer in solution. Bottom-up analysis is not particularly limited by protein mass, and due to the large size of $\mathrm{ADH}$, there is a clear 'core' region which is effectively shielded from the solvent. ADH contains two $\mathrm{Zn}^{2+}$ ions per monomer (so eight in total for the tetramer); however, this does not interfere with the labelling reaction, as $\mathrm{Zn}$ is redox-inactive under these conditions.

Overall, less extensive modification was observed in ADH compared to myoglobin, possibly reflecting the larger size of the tetramer (see Figure 5). In total, eleven modification sites were identified (note that each chain comprises 347 residues). Comparing the identified modification sites to the accessible surface based on the crystal structure [46], most of the oxidation sites were indeed solvent-exposed, which supports our hypothesis of selective labelling without major structure disruption on the timescale we used. Two exceptions, for which oxidation was observed despite the residues not being classified as accessible, were Met270 and Cys277. For Met270, we found that significant oxidation occurred even during the analysis of a sample where no oxidative footprinting was performed, indicating that this was likely an artefact that occurred on the peptide level during sample preparation or the electrospray process. 


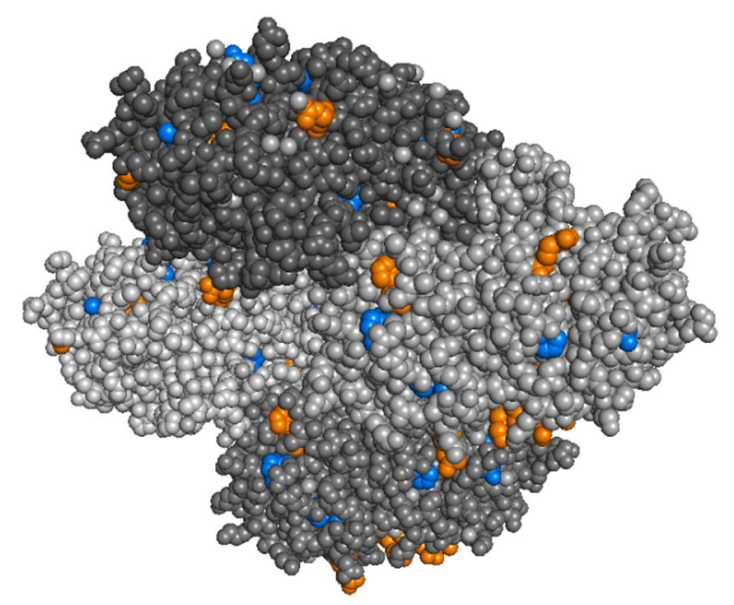

Figure 5. Labelling sites in ADH, indicated in the crystal structure (PDB accession code: 4W6Z) with the same colour code as in Figure 4.

In contrast, Cys277 was not oxidised in a control sample that was not exposed to hydroxyl radicals, indicating that this was indeed a result of the footprinting reaction. This was surprising, as our calculations based on the crystal structure indicated that this residue was not solvent-accessible; however, it should be noted that this residue is located in a cleft facing the solvent, rather than being involved in the protein-protein interface. The nearby residues Ala272 and Gly273 are classified as solvent-accessible in the crystal structure, and the residues in this region have relatively high crystallographic B-factors in the 38-46 $\AA^{2}$ range, indicating significant local conformational flexibility. As such, it is plausible that Cys 277 occasionally comes into contact with the solvent during the normal 'breathing' of the protein structure and, given the high intrinsic reactivity of cysteine toward hydroxyl radicals, this could account for the oxidation of this residue that we observed. In this way, it is plausible that our method indirectly provides insights into transient states that are normally 'invisible'. Overall, our results for ADH support the notion that oxidative labelling under the conditions used by us, indeed, selectively modifies the solvent-accessible surface.

\subsection{FKBP51 and FKBP12: Key Interactions Drive Remarkable Structural Stabilisation}

The immunophilin FKBP51 (see Figure 6A) belongs to the class of FK506-binding proteins and is a potentially important drug target in the context of depression, obesityrelated diabetes, and chronic pain [38,39]. Drug development is hindered by the presence of homologues in the human body, including FKBP52 and FKBP12, which poses a challenge for designing selective ligands that avoid off-target effects [40]. One of the most promising ways for selective inhibition of FKBP51 is the targeting of minor conformational states, which exhibit a greater structural difference between homologues than the most abundant conformation [47]. Understanding such differences in the dynamics of protein structure and identifying possible transient binding sites is a major challenge for structural biology and difficult to achieve with conventional methods [48]. Given the importance of this protein family for human health, we decided to investigate two homologues with our footprinting method-FKBP12 (11.8 kDa, Figure 6B) and FKBP51. For the latter, rather than the full-length protein, a $14.0 \mathrm{kDa}$ construct was used consisting of the FKBP-type peptidyl-prolyl cis-trans isomerase (PPIase) domain (called the FK1 domain), and this construct will be referred to as FKBP51FK1 in the rest of this work. Both proteins were analysed in their free state, as well as bound to two different ligands: SAFit1 and FK[4.3.1] 16h [40,41]. Binding affinity $\left(\mathrm{K}_{\mathrm{i}}\right)$ to FKBP12 is approximately $163 \mathrm{nM}$ for SAFit1 and $1.8 \mathrm{nM}$ for FK[4.3.1]-16h. Binding affinity to FKBP51 is approximately $4 \mathrm{nM}$ for SAFit1 and $57 \mathrm{nM}$ for FK[4.3.1]-16h [41,49]. 
A

FKBP51FK1

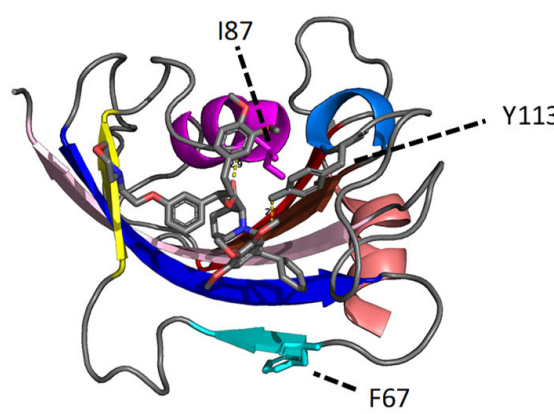

B $\quad$ FKBP12

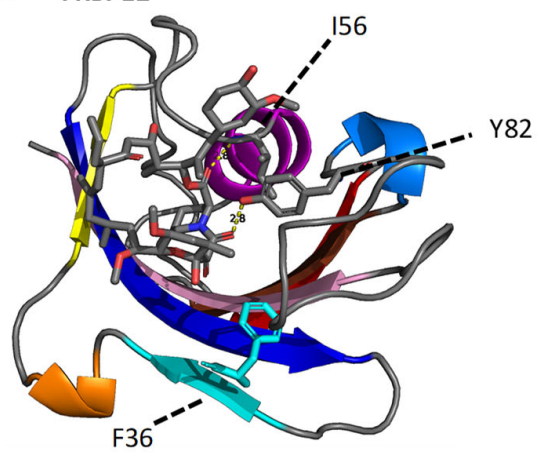

C

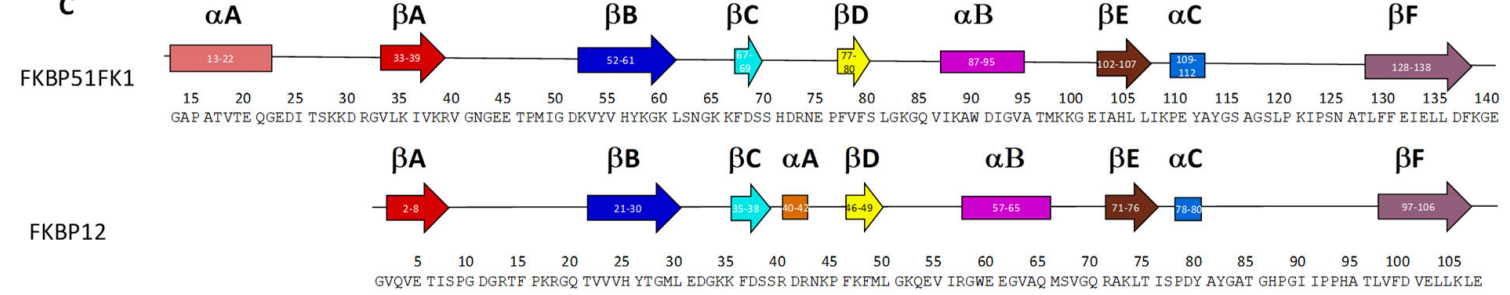

Figure 6. (A) Crystal structure of FKBP51FK1 in complex with the SAFit analogue iFit4 (Protein Data Bank accession code 4TW7), with key interacting amino acid residues labelled with a dashed line. (B) Crystal structure of FKBP12 in complex with FK506 (accession code 1FKJ), with key interacting amino acid residues labelled with a dashed line. (C) Sequence overview for FKBP51FK1 and FKBP12, where homologous sequence regions are aligned. Secondary structure elements are colour-coded and correspond to the same colour in the crystal structures.

In our initial experiments with the FK506-binding proteins, we found that reproducibility between replicate experiments was somewhat poor, leading to wide confidence intervals on the degree of oxidation, particularly for the complex with FK[4.3.1]-16h (data not shown). Manual inspection of the spectra revealed elution of a significant amount of intact protein near the end of the LC gradient in samples where ligand was present, indicating incomplete digestion. We hypothesised that this was due to the protein structure being sufficiently stabilised by interactions with the ligand to resist unfolding under our standard denaturing conditions (incubation with $6 \mathrm{M}$ urea at $28^{\circ} \mathrm{C}$ for one hour). This apparently led to inefficient digestion of largely folded protein by trypsin, somewhat similar to a limited proteolysis experiment $[50,51]$.

Given the suboptimal reproducibility in these initial experiments, we discarded the results from bottom-up analysis and repeated the experiments with more aggressive denaturation conditions (vide infra); however, we did wish to further test the hypothesis of ligand-induced stabilisation toward chemical denaturation. For this, we performed MS of intact FKBP12 in the presence of FK[4.3.1]-16h (the sample that showed the highest abundance of remaining intact protein after digestion) with different concentrations of acetonitrile (data not shown). Under native-like conditions with no organic solvent, the protein was mostly in its ligand-bound form and was observed at low charge states, as commonly observed in native MS. Intriguingly, we found that a significant amount of low-charge-state (likely compact) protein was observed until $45 \%$ acetonitrile was added, and even a non-negligible amount of protein-ligand complex was still present under these conditions. In contrast, for the ligand-free FKBP12, a 'steady-state' of mostly high-chargestate (likely unfolded) protein was observed at $35 \%$ organic solvent, and this did not change until $>50 \%$, at which point precipitation of the protein occurred. This observation supports the notion that ligand binding stabilised the protein toward denaturation and subsequent enzymatic digestion. For comparison, the presence of $30 \%$ acetonitrile was sufficient to cause myoglobin to mostly lose its haem group. To avoid incomplete protein digestion and ensure reproducibility, the experiments were repeated, with the denaturation step being extended to six hours. Three independent samples were prepared for each condition (two 
proteins, each in their free state and bound to both ligands), and each sample was injected onto the column twice (i.e., a total of 36 injections were performed).

As before, aliquots were taken and intact mass measurements performed immediately after the oxidative footprinting reaction (Figure 7). This revealed strongly reduced reactivity toward oxidation upon ligand binding, consistent with ligand-induced protection. In addition to the insight into the global labelling extent, a further benefit of this intact mass measurement was that it demonstrated that reaction between FKBP12 and hydroxyl radicals mostly occurred through 'simple' oxidation rather than side reactions that have been reported in the literature [10]. This was revealed through the observation of a pattern of mass increases in steps of $16 \mathrm{Da}$, up to an addition of $48 \mathrm{Da}$ (more extensively oxidised protein was visible in the spectrum, but at lower abundance). With this knowledge, we were able to significantly speed up our data analysis (a necessity, given the sizeable data set) by focussing on peptides with these modifications. In practice, addition of a single oxygen atom was by far the most common modification at the peptide level, which is consistent with global addition of only a few oxygen atoms to the entire protein.

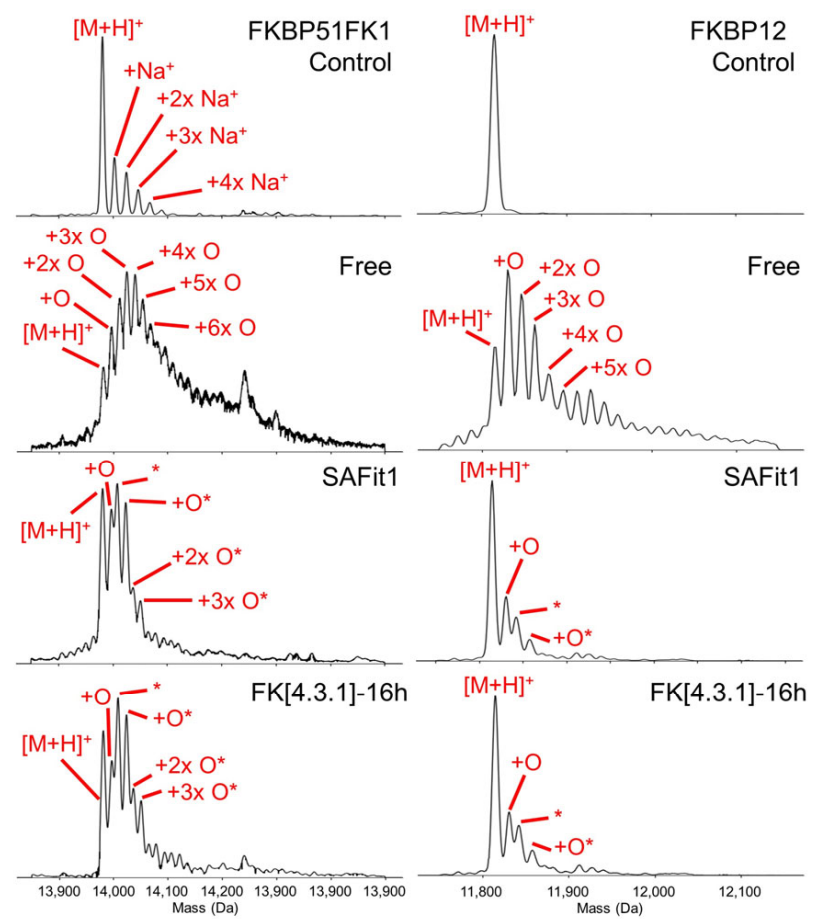

Figure 7. Intact mass measurement of FKBP51FK1 and FKBP12 (deconvoluted spectra shown) under denaturing conditions before (control; top panel) and after oxidative footprinting, either in the absence (second row; 'free' protein) or presence of ligands SAFit1 and FK[4.3.1]-16h. Peaks labelled with an asterisk carry an additional modification of 27.01 Da.

Peptides that were detected with sufficient signal-to-noise for quantification covered $92 \%$ of the sequence of FKBP12 and $88 \%$ of the sequence of FKBP51FK1. Oxidation sites were identified qualitatively with single-residue specificity through tandem MS; however, signal-to-noise in fragment spectra was insufficient to determine site-specific changes in oxidation level with statistical significance; therefore, quantitative analysis was limited to the peptide level. Results of this analysis are summarised in Figure 8. The fact that three samples were prepared for each condition allowed us to evaluate the reproducibility of our method in this case. Visually, it is apparent that most error bars are small; more quantitatively, the median coefficient of variation for the fraction of oxidised peptides for FKBP51FK1 was 10.2\%. A similar value (10.5\%) was observed for FKBP12 peptides. 
A

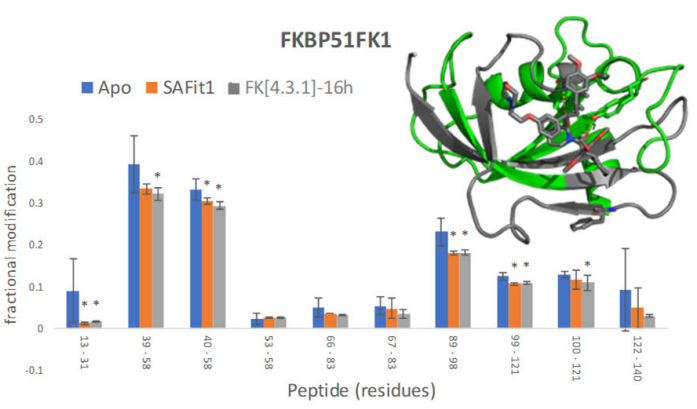

B

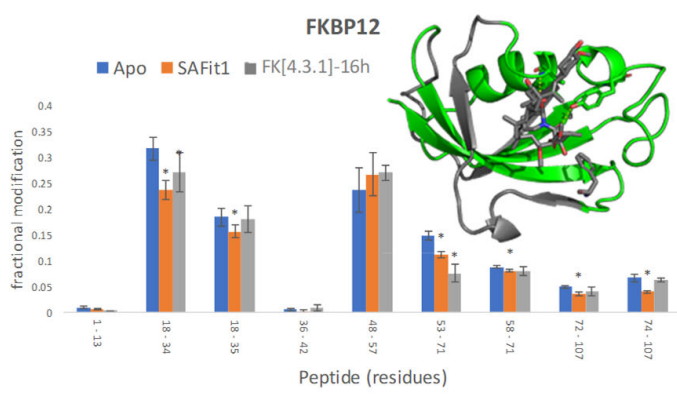

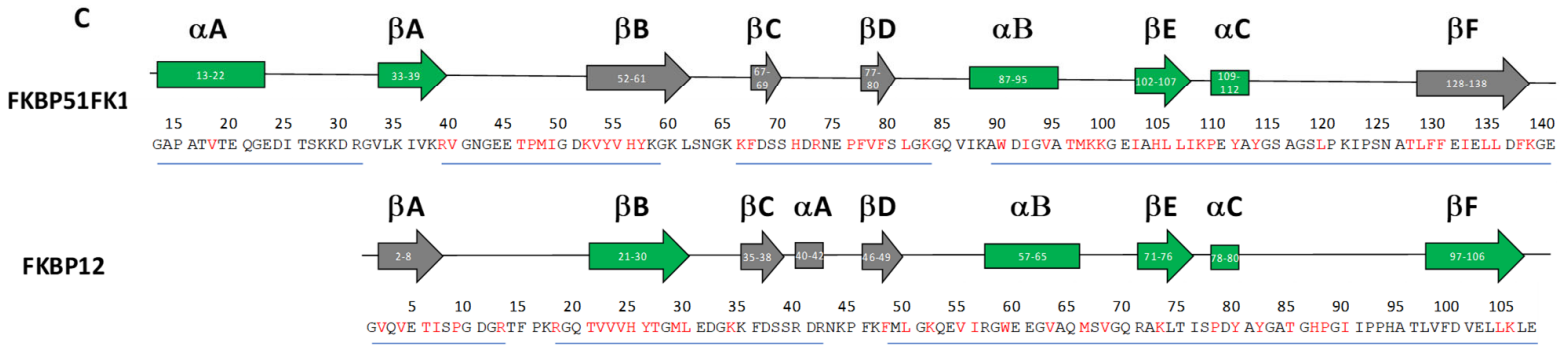

Figure 8. Results of the peptide-level analysis of the FK506-binding proteins: (A) fractional oxidative modification of the peptides of FKBP51FK1 for the apo protein as well as SAFit1- and FK[4.3.1]-16h-bound protein, in which statistically significant $(p<0.05)$ differences between ligand-bound and -free states are indicated with an asterisk $\left(^{*}\right)$. Insets show crystal structures with regions that show reduced oxidation after binding of either ligand in green. (B) Fractional modification of the peptides of FKBP12 for the apo protein, as well as ligand-bound states. (C) Sequence overview for FKBP51FK1 and FKBP12, with sequence regions covered by the observed peptides underlined. Secondary structure elements are labelled as in Figure 6. Elements that show reduced oxidation after ligand binding are coloured green in Panel (C), and unaffected elements are in grey (same colour code as the insets in Panel (A); no regions were observed where ligand binding led to increased oxidative labelling). Detected oxidative labelling sites are coloured red in the sequence.

The first thing that stands out from these results is the overall reduction in degree of oxidation upon ligand binding for both proteins. This is consistent with the intact mass measurements and could be partly due to direct shielding of reactive residues by the ligands, but also supports the hypothesis that overall structural compaction led to the incomplete digestion of ligand-bound protein that we observed in our initial attempts. Analysing the results in more detail, some interesting differences between both ligands, and between both proteins become apparent. In this discussion, the homology between both proteins is important; specifically, it should be noted that residues 1-106 of FKBP12 show a striking similarity to residues $32-137$ of FKBP51FK1. Despite this, even in the ligand-free form, some differences are apparent. Most striking is the very limited degree of oxidation in peptides spanning residues 53-83 in FKBP51FK1, corresponding to the region 22-52 in FKBP12, where significant oxidation was observed. We attribute this to the presence of the N-terminal extension of 31 residues in FKBP51FK1, which appears to shield part of the main $\beta$-sheet region of the protein from the solvent in the crystal structure (see Figure 6A). Perhaps due to this limited initial degree of oxidation in FKBP51FK1, no statistically significant reduction was observed in this region after ligand binding, while binding of SAFit1, but not FK[4.3.1]-16h, did lead to a significant protective effect in the 18-34 region of FKBP12, possibly reflecting a greater degree of direct shielding by the bulkier SAFit1.

An alternative, more intriguing explanation for this behaviour than a simple steric effect involves the fact that binding of SAFit1 to FKBP51FK1 requires the side chain of residue Phe67 to be displaced, and this alternative conformation is at the core of the ability of this type of ligand to distinguish between homologues [40]. The binding affinity of SAFit1 to FKBP12, where Phe36 is the counterpart to Phe67 in FKBP51FK1 (see Figure 6), is an order of magnitude lower than to FKBP51FK1 [41,49]. Interestingly, in both cases the 
key phenylalanine residue is part of a $\beta$-sheet, with the adjacent strand (labelled as ' $\beta B^{\prime}$ in Figures 6 and 8) composed of residues 21-30 in FKBP12 and residues 52-61 in FKBP51FK1. In this context, the increased protection observed in the $\beta \mathrm{B}$ region of FKBP12 after binding of SAFit1 compared to FK[4.3.1]-16h (which binds to an apo-like conformation), and the lack of such protection in the corresponding region of FKBP51FK1 upon binding of either ligand, could indicate that a more significant structural rearrangement is required for FKBP12 than for FKBP51 to adopt the conformation that can efficiently bind SAFit1. It is plausible that this need to undergo a more significant rearrangement makes the SAFit1binding conformation less favourable for FKBP12, which might contribute to the previously established lower binding affinity.

The N-terminal extension itself also exhibits significant protection upon ligand binding to FKBP51FK1, as reflected by the decrease in oxidation in the peptide spanning residues 13-33. This was surprising as, in the crystal structure, this region is fairly distant from the ligand binding site. This effect may be a result of an indirect stabilization caused by the adjacent beta strands that are protected upon ligand binding. In both FKBP12 and FKBP51FK1, the C-terminal portion of the protein showed significant protection after ligand binding. This is unsurprising and can largely be attributed to steric effects, as this region contains many residues that are either part of, or close to, the binding site. Of note is the protection of the peptide with residues 89-98 in FKBP51FK1 and, similarly, that with residues 53-71 in FKBP12. These span an $\alpha$-helix $(\alpha \mathrm{B})$ containing, or being close to, a key interacting amino acid residue (Ile56 in FKBP12 and Ile87 in FKBP51FK1) that forms a strong hydrogen bond with both ligands through its amide nitrogen atom [49,52-54]. Furthermore, a very reactive tryptophan (based on both the inherent reactivity of the side chain toward oxidative labelling, and the direct observation, as shown in Figure 8C) that is located within the binding pocket and directly exposed to solvent in the absence of a ligand is located in this region. The shielding of this reactive tryptophan (Trp59 in FKBP12; Trp90 in FKBP51FK1), combined with the strong interaction of the isoleucine with the ligand, causes one of the most significant protections of the protein.

\section{Discussion}

We have shown that oxidative labelling through Fenton chemistry can be employed for structural characterisation of a set of model proteins, with a reaction time of only a few seconds, and that conformational changes are reflected in the modification pattern. For the smaller (11-18 kDa) proteins we studied, extensive oxidation was observed, and it was demonstrated how the oxidation pattern correlated to protein structure, including dynamic aspects. Information was sparser on the $148 \mathrm{kDa} \mathrm{ADH}$ tetramer, where fewer oxidation sites were identified. A plausible explanation for this is that the reaction rate was limited by the concentration of Fenton reagents (specifically Fe(II)-EDTA at $94 \mu \mathrm{M}$ ) under these conditions, leading to approximately the same number of oxidation events being distributed over a much larger number of reactive residues, resulting in the observed greater selectivity for highly reactive sites. A possible way to address this in the future and obtain a consistent degree of oxidation across a range of protein masses would be to use a consistent mass-based concentration for proteins in the labelling solution, rather than consistent molarity.

For the ADH tetramer, we showed that oxidation occurs primarily at the exposed protein surface, in agreement with other hydroxyl radical footprinting techniques. In the cases of myoglobin and the two FK506-binding proteins we tested, there were clear differences in the oxidation pattern between the ligand-bound and ligand-free state of the protein. For myoglobin specifically, a key histidine residue that binds to the native iron centre was highly reactive in the apo state, and protected in the holo state. Furthermore, oxidation was observed of residues within the binding pocket of the haem group, but exclusively on the side of the plane of this prosthetic group at which biologically relevant ligands, such as oxygen, bind. It is reasonable to assume that this reflects increased conformational flexibility on this side of the haem group, which is necessary to accommodate the 
exchange and transport of gas molecules by myoglobin. This supports the hypothesis that our method is able to inform on dynamic aspects of protein conformation, rather than just a static lowest-energy structure.

In addition to these strengths, we also identified several practical limitations to the method presented in this work. The reaction time for our oxidative footprinting method is limited in practice to several seconds, which leads to a degree of ensemble averaging and precludes the probing of protein structure on a microsecond timescale, as is possible in labelling methods based on photolysis. The use of microfluidics in future studies could significantly reduce the reaction time [55,56], but-even assuming the extent of the labelling reaction on such a short timescale would be sufficient to obtain structural information-this approach would still be orders of magnitude slower than FPOP.

Another potential concern is the effect of sulphur-containing residues. While this did not pose an issue for most methionine- or cysteine-containing peptides in our hands, we did find that, in the case of $\mathrm{ADH}$, the residue Met270 was consistently and spontaneously oxidised-possibly during sample handling or the electrospray process-even in control samples. This needs to be carefully controlled and could pose a challenge for the analysis of methionine- or cysteine-rich proteins by oxidative footprinting, regardless of the exact chemistry used to generate hydroxyl radicals. The main bottleneck we identified in implementing this type of experiment was data analysis. Given that most amino acid residues are at least somewhat reactive toward hydroxyl radicals, and that many residue types are able to undergo several competing reactions under these conditions, the number of (modified) peptides that need to be matched to an experimental data set, even for a known protein sequence, quickly becomes very large. Even using a high-end desktop PC, searching for all possible reaction products is not feasible, or is at least sufficiently time-consuming to be impractical, and an optimal trade-off between 'complete' data analysis and processing time needs to be determined empirically in the absence of access to high-performance computing. For quantitative analysis of oxidised peptides from FK506-binding proteins, we found that a targeted software package (pepFoot) provided good performance while requiring far less computational power than MaxQuant [44,45,57]. In future work, we will further optimise the data processing workflow, as well as extend the method to a greater set of protein-ligand systems, and compare it to other, more conventional labelling techniques.

Combining bottom-up proteomics analysis with intact mass measurement and/or topdown fragmentation can be helpful for optimising the analytical workflow, as it provides a clue regarding the overall extent of modification and possibly some of the labelling sites, which can inform the subsequent more in-depth bottom-up data analysis. Similarly, especially when studying ligand binding, native mass spectrometry can provide important complementary insight to oxidative footprinting. Finally, incomplete protein digestion complicates the data analysis and potentially leads to poor reproducibility, but, at the same time, can be indicative of high structural stability, similar to limited proteolysis approaches developed in recent years. Combining the insights from all the aforementioned data points—and with insights from conventional structural biology methods-leads to an improved understanding of the 'four-dimensional' structure of a protein in solution. We believe that the underexplored labelling method used in this work shows sufficient promise to be further developed in the future as a technique for hydroxyl radical footprinting with low barriers to entry compared to radiolysis. As such, this will potentially provide a valuable addition to the toolset of researchers interested in MS-based conformational protein analysis.

\section{Materials and Methods}

\subsection{Proteins, Reagents and Solvents}

Most materials were acquired from commercial suppliers: HPLC-grade acetonitrile (Roth, Karlsruhe, Germany, HN44.2); LC-MS grade acetonitrile (Supelco LiChrosolv, Darmstadt, Germany, 1.00029.2500); alcohol dehydrogenase (Sigma-Aldrich, St. Louis, MI, USA, A3263); ammonia, 30\% w/w (Sigma-Aldrich, St. Louis, MI, USA, 221228); ammo- 
nium acetate, 7.5 M (Sigma-Aldrich, St. Louis, MI, USA, A2706); apo-myoglobin (SigmaAldrich, St. Louis, MI, USA, A8673); L-ascorbic acid (Sigma-Aldrich, St. Louis, MI, USA, 255564); Discovery ${ }^{\circledR}$ DSC-18 SPE Tubes (Sigma-Aldrich, St. Louis, MI, USA, 62602-U); 1,4dithiothreitol (Roth, Karlsruhe, Germany, 6909.1); $\mathrm{H}_{4}$ EDTA (Sigma-Aldrich, St. Louis, MI, USA, 431788); formic acid (Fisher Chemical, Waltham, MA, USA, A117-50); holo-myoglobin (Sigma-Aldrich, St. Louis, MI, USA, M0630); hydrogen peroxide, 30\% w/w (Sigma-Aldrich, St. Louis, MI, USA, 95321); iodoacetamide (Sigma-Aldrich, St. Louis, MI, USA, I6125); iron(II)-chloride tetrahydrate (Sigma-Aldrich, St. Louis, MI, USA, 44939); Pierce $^{\mathrm{TM}}$ Trypsin $^{2}$ Protease (Thermo Fisher, Waltham, MA, USA, 90058); triethylammonium bicarbonate buffer (Fluka, St. Louis, MI, USA, 17902); trifluoroacetic acid (Roth, Karlsruhe, Germany, P088.3); urea (Roth, Karlsruhe, Germany, 2317.1). FK506-binding proteins were expressed based on previously described methods [58,59].

\subsection{Oxidative Footprinting}

Protein stock solutions of FKBP12 and FKBP51FK1 in 20 mM HEPES, pH 8.5, and $150 \mathrm{mM} \mathrm{NaCl}$ were diluted in $200 \mathrm{mM}$ ammonium acetate to $40.7 \mu \mathrm{M}$. Ligand stock solutions were prepared in DMSO at 250 times the final concentration and prediluted to 50 times the final concentration in acetonitrile. A total of $49.2 \mu \mathrm{L}$ of the protein solution and $0.8 \mu \mathrm{L}$ of the ligand solution or $200 \mathrm{mM}$ ammonium acetate were mixed to achieve a final protein concentration of $40 \mu \mathrm{M}$ and ligand concentration of $80 \mu \mathrm{M}$, and incubated for $15 \mathrm{~min}$ at room temperature, after which the oxidative footprinting reaction was initiated.

For each reaction, fresh solutions were prepared of $0.3 \mathrm{M}$ hydrogen peroxide, $37.5 \mathrm{mM}$ L-ascorbic acid, $187.5 \mathrm{mM}$ thiourea, and iron(II)-EDTA solution. The $0.3 \mathrm{M}$ hydrogen peroxide solution was prepared by diluting a $30 \% w / w$ stock solution with milliQ water. The ascorbic acid solution was prepared by dissolving $6.6 \mathrm{mg}$ of ascorbic acid in $1 \mathrm{~mL}$ of milliQ water and neutralising with $2.3 \mu \mathrm{L}$ of $30 \% w / w$ ammonia. Note that ascorbic acid is oxidation-sensitive in air and that this solution was stable for approximately one hour at room temperature. For a $187.5 \mathrm{mM}$ thiourea solution, we dissolved $14.27 \mathrm{mg}$ of thiourea in $1 \mathrm{~mL}$ of $200 \mathrm{mM}$ ammonium acetate solution. The iron(II)-EDTA solution was prepared using a stock solution of $3 \mathrm{mM} \mathrm{H}_{4}$ EDTA with $12 \mathrm{mM}$ ammonia. A $1.5 \mathrm{mM}$ iron(II)-chloride solution in milliQ water was made fresh for the reaction. Equal volumes of the EDTA stock solution and the iron(II)-chloride solution were mixed in a reaction tube to obtain the iron(II)-EDTA solution.

For the oxidative footprinting reaction, $50 \mu \mathrm{L}$ of a $40 \mu \mathrm{M}$ protein solution (in $200 \mathrm{mM}$ ammonium acetate) was pipetted into a $500 \mu \mathrm{L}$ reaction tube. Next, $10 \mu \mathrm{L}$ of the iron(II)EDTA solution was added, followed by $10 \mu \mathrm{L}$ of the L-ascorbic acid solution. Immediately after subsequently adding $10 \mu \mathrm{L}$ of the $0.3 \mathrm{M}$ hydrogen peroxide solution, the reaction tube was vortexed and the reaction was allowed to proceed for $15 \mathrm{~s}$. After $15 \mathrm{~s}$, the reaction was quenched by adding $20 \mu \mathrm{L}$ of the thiourea solution into the reaction tube and vortexing. The final concentration of the protein after the reaction was 5 to $20 \mu \mathrm{M}$ with $140 \mathrm{mM}$ ammonium acetate.

\subsection{Tryptic Digest}

For digestion, $300 \mu \mathrm{L}$ of an $8 \mathrm{M}$ urea solution in $50 \mathrm{mM}$ TEAB, $\mathrm{pH} 8.5$, with $100 \mathrm{mM}$ $\mathrm{NaCl}$, as well as $8 \mu \mathrm{L}$ of a $0.5 \mathrm{M}$ solution of DTT were added to the oxidative footprinting reaction mixture. After incubating the mixture for one hour at $28^{\circ} \mathrm{C}, 1 \mathrm{~mL}$ of $50 \mathrm{mM} \mathrm{TEAB}$, $\mathrm{pH} 8.5$, and $1.2 \mu \mathrm{L}$ of $1 \mathrm{mg} / \mathrm{mL}$ trypsin in $50 \mathrm{mM}$ acetic acid were added in succession. The digest was incubated overnight at $37^{\circ} \mathrm{C}$. After the samples cooled down to room temperature, trifluoroacetic acid was added until the solution was at a $\mathrm{pH}$ value of 2 . A $100 \mathrm{mg}$ C18-SPE cartridge was conditioned with $1 \mathrm{~mL}$ HPLC-grade acetonitrile and $1 \mathrm{~mL}$ $0.6 \% v / v$ TFA solution with milliQ water. Next, the sample was loaded on the cartridge and washed with $1 \mathrm{~mL} 0.6 \% v / v$ TFA solution in milliQ water. Elution was performed with $1 \mathrm{~mL}$ of an $80 \% v / v$ acetonitrile solution. The eluate was dried in a vacuum centrifuge 
(UniVapo 150H; UniEquip, Planegg, Germany) and redissolved in $100 \mu \mathrm{L}$ of a $5 \% v / v$ acetonitrile solution containing $0.1 \% v / v$ formic acid.

\subsection{LC-MS/MS Analysis}

LC-MS/MS analysis was performed with an LTQ Orbitrap XL (Thermo Fisher Scientific, Waltham, MA, USA) controlled by Xcalibur 2.1 and a micro-LC system consisting of a Micro Pro syringe pump (Eldex Laboratories, Napa, CA, USA), and an Endurance autosampler (Spark Holland, Emmen, The Netherlands) controlled by the Endurance software. Acquisitions were started upon injection by contact closure.

Samples $(5 \mu \mathrm{L})$ were injected with a flushed loop injection and peptides were separated on a ZORBAX StableBond C18, $0.3 \times 150 \mathrm{~mm}, 3.5 \mu \mathrm{m}$ column (Agilent, Santa Clara, CA, USA) at a flow rate of $5 \mu \mathrm{L} / \mathrm{min}$ using the following gradient: linear gradient from $5 \% \mathrm{~B}$ to $60 \% \mathrm{~B}$ in $60 \mathrm{~min}, 10 \mathrm{~min}$ linear gradient to $100 \% \mathrm{~B}, 10 \mathrm{~min}$ at $100 \% \mathrm{~B}$ isocratic, followed by re-equilibration at $5 \% \mathrm{~B}$ for $15 \mathrm{~min}$, with solvent $\mathrm{A}$ being water with $0.1 \%$ formic acid and solvent $\mathrm{B}$ being acetonitrile with $0.1 \%$ formic acid.

The mass spectrometer was operated in a data-dependent mode with a precursor scan in the Orbitrap with a resolution of 60,000 at $m / z 400$, followed by fragmentation of peptide ions with a charge state of 2 or higher, giving rise to the four most intense signals in the ion trap using CID with a normalized collision energy of 25. Dynamic exclusion was enabled and set to a repeat count of 2 with a repeat duration of $30 \mathrm{~s}$, the exclusion list size was 200, and the exclusion duration was $50 \mathrm{~s}$. The ESI source was operated with 10 units of sheath gas flow rate, a spray voltage of $4 \mathrm{kV}$, a capillary temperature of $300^{\circ} \mathrm{C}$, a capillary voltage of $3 \mathrm{~V}$, and tube lens set to 30 .

For intact mass measurements and for native MS, including the experiments with different concentrations of acetonitrile, $10 \mu \mathrm{L}$ of sample was loaded into a glass needle that was pulled to a tip of ca. 1- $\mu \mathrm{m}$ orifice diameter with a P97 Flaming/Brown type micropipette puller (Sutter Instrument Co., Novato, CA, USA), starting from 1.2-mm thinwalled glass capillaries (World Precision Instruments, Friedberg, Germany). Ionisation was then performed using a home-built nano-electrospray source that was coupled to the LTQ Orbitrap XL instrument. Intact protein spectra were deconvoluted with UniDec [60].

\subsection{Data Analysis Using MaxQuant}

The MaxQuant calculations were separated into two parts and, in all cases, a precursor mass accuracy of $4.5 \mathrm{ppm}$ was used. In the first part with one calculation run, the unmodified peptides were identified. Only the fasta file of the target protein was used to search against. The default settings were used, with the following exceptions: no fractions-yes; min. peptide length -5 ; max. peptide mass (Da)—4800; min. score for modified peptides— 0 ; second peptides—off; unknown MS/MS match tolerance and unit$0.5 \mathrm{Da}$; unknown MS/MS de novo tolerance and unit-0.25 Da; unknown deisotoping-off. For every identified peptide, a separate fasta file was then created for use in the second step. This step comprised three calculation runs to determine the modifications. The first calculation run included +15.995 Da (+O) for M, C, W, Y, F, K, R, Q, D, T, S, A, E, L, I, K, H, $\mathrm{N}, \mathrm{V}$ and $+31.990 \mathrm{Da}(+2 \times \mathrm{O})$ for $\mathrm{M}, \mathrm{C}, \mathrm{W}, \mathrm{Y}, \mathrm{F}$, both as variable modifications additional to carbamidomethyl- and acetyl-(N-term) modifications. The second calculation run included $+15.995 \mathrm{Da}(+\mathrm{O})$ for $\mathrm{W}, \mathrm{C}, \mathrm{M}, \mathrm{Y}, \mathrm{F}, \mathrm{H} ;+47.985 \mathrm{Da}(+3 \times \mathrm{O})$ for C, W, Y, F; $-43.053 \mathrm{Da}(+\mathrm{O}$ $-5 \times \mathrm{H}-3 \times \mathrm{N}-\mathrm{C})$ for $\mathrm{R} ;-32.008 \mathrm{Da}(+\mathrm{O}-\mathrm{S}-4 \times \mathrm{H}-\mathrm{C})$ for $\mathrm{M} ;-30.011 \mathrm{Da}(-2 \times \mathrm{H}-\mathrm{C}-\mathrm{O})$ for $\mathrm{E}$, $\mathrm{D} ;+13,9792645(+\mathrm{O}-2 \mathrm{H})$ for $\mathrm{L}, \mathrm{I}, \mathrm{V}, \mathrm{P}, \mathrm{R}, \mathrm{K}, \mathrm{E}, \mathrm{Q}$; and $-2.016 \mathrm{Da}(-2 \mathrm{xH})$ for $\mathrm{T}, \mathrm{S}$, all as variable modifications additional to carbamidomethyl- and acetyl-(N-term) modifications. The last calculation run included +15.995 $\mathrm{Da}(+\mathrm{O})$ for $\mathrm{W}, \mathrm{C}, \mathrm{M}, \mathrm{Y}, \mathrm{F}, \mathrm{H} ;-10.032 \mathrm{Da}(+2 \times \mathrm{O}$ $-2 \times \mathrm{H}-2 \mathrm{xN}-\mathrm{C})$ for $\mathrm{H} ;-4.979 \mathrm{Da}(+2 \mathrm{xO}-\mathrm{H}-\mathrm{C}-\mathrm{N})$ for $\mathrm{H} ;-22.032 \mathrm{Da}(+2 \mathrm{xO}-2 \mathrm{xH}-2 \mathrm{xC}-2 \times \mathrm{N})$ for $\mathrm{H}$; and $-23.016 \mathrm{Da}(+\mathrm{O}-\mathrm{H}-\mathrm{N}-2 \times \mathrm{C})$ for $\mathrm{H}$, all as variable modifications additional to carbamidomethyl- and acetyl-(N-term) modifications. The default settings were used, with the following exceptions: no fractions-yes; digestion mode-no digestion; include contaminates—off; min. peptide length—5; max. peptide mass (Da)—4800; min. score for 
modified peptides—0; second peptides—off; unknown MS/MS match tolerance and unit$0.5 \mathrm{Da}$; unknown MS/MS de novo tolerance and unit— $0.25 \mathrm{Da}$; unknown deisotoping—off. For positive identification of an oxidatively modified residue, while avoiding false positive results, we typically required that a $+15.995 \mathrm{Da}(+\mathrm{O})$ modification was detected two times in different modified peptides, or, alternatively, that a product from a side reaction of oxidative footprinting was found in addition to a $+15.995 \mathrm{Da}(+\mathrm{O})$ modification. Finally, an additional search was run against the entire UniProt database to ensure that peptides identified as oxidised were genuine and not false positives due to overlap with peptides from protein contaminants (note that such overlap would need to occur at both the MS and MS/MS level and is, therefore, very unlikely). Other than the trypsin used for proteolysis and a low-level contamination of keratin in a handful of samples, no other contaminants were found, which confirms sample purity and rules out false positives.

\subsection{Quantifying Peptides Using pepFoot}

Raw files were converted to the mz5 format using MSConvert and then processed in the pepFoot software $[23,24,57]$ using the following parameters: modifications-carbamidomethyl, variable modifications - oxidation (+ oxygen), digestion - trypsin, peptide length - 5-40, peptide charge $-1-6$, \# missed cleavages-2, MS tolerance-20 ppm. Extracted ion chromatograms of identified peptides by MaxQuant in acceptable abundance (S/N > 9:1) were then integrated for the modified and unmodified peptide, and the degree of modification was calculated by the software for apo and holo proteins.

Author Contributions: F.L., T.N. and T.H. designed the study. T.N. and T.H. performed oxidative footprinting and LC-MS experiments, as well as data analysis and visualisation. T.N. performed native MS and intact mass measurements. C.M. performed expression of FK506-binding proteins. F.H. and F.L. supervised the project. F.L. wrote the first draft of the manuscript. All authors have read and agreed to the published version of the manuscript.

Funding: Funding by the LOEWE project TRABITA funded by the Hessian Ministry of Higher Education, Research, and the Arts (HMWK) is gratefully acknowledged. T.H. was supported by the Kooperative Promotionsplattform, financed by the HMWK. We acknowledge support by the Deutsche Forschungsgemeinschaft (DFG-German Research Foundation) and the Open Access Publishing Fund of Technical University of Darmstadt.

Institutional Review Board Statement: Not applicable.

Informed Consent Statement: Not applicable.

Data Availability Statement: The data and materials underlying this article will be shared on request to the corresponding author.

Acknowledgments: We are grateful to Tanja Habeck (TU Darmstadt) for help with the initial optimisation of LC-MS experiments, and to Kevin Kretschmer (TU Darmstadt) for assistance with the initial work with the nano-ESI source. We thank Günes Barka from SunChrom GmbH for supporting us with the micro-LC. Alexander Schießer and the MS facility of the Department of Chemistry of TU Darmstadt are gratefully acknowledged for access to the Orbitrap instrument. We are grateful to the reviewers for their insightful comments.

Conflicts of Interest: The authors declare no conflict of interest.

\section{References}

1. Konijnenberg, A.; Butterer, A.; Sobott, F. Native ion mobility-mass spectrometry and related methods in structural biology. Biochim. Biophys. Acta 2013, 1834, 1239-1256. [CrossRef]

2. Politis, A.; Stengel, F.; Hall, Z.; Hernandez, H.; Leitner, A.; Walzthoeni, T.; Robinson, C.V.; Aebersold, R. A mass spectrometrybased hybrid method for structural modeling of protein complexes. Nat. Methods 2014, 11, 403-406. [CrossRef]

3. Leney, A.C.; Heck, A.J. Native Mass Spectrometry: What is in the Name? J. Am. Soc. Mass Spectrom. 2017, 28, 5-13. [CrossRef]

4. Robinson, C.V. Mass spectrometry: From plasma proteins to mitochondrial membranes. Proc. Natl. Acad. Sci. USA 2019, 116, 2814-2820. [CrossRef] [PubMed] 
5. Allison, T.M.; Barran, P.; Cianferani, S.; Degiacomi, M.T.; Gabelica, V.; Grandori, R.; Marklund, E.G.; Menneteau, T.; Migas, L.G.; Politis, A.; et al. Computational Strategies and Challenges for Using Native Ion Mobility Mass Spectrometry in Biophysics and Structural Biology. Anal. Chem. 2020, 92, 10872-10880. [CrossRef] [PubMed]

6. Zhou, M.; Lantz, C.; Brown, K.A.; Ge, Y.; Pasa Tolic, L.; Loo, J.A.; Lermyte, F. Higher-order structural characterisation of native proteins and complexes by top-down mass spectrometry. Chem. Sci. 2020, 11, 12918-12936. [CrossRef]

7. Groves, K.; Ashcroft, A.E.; Cryar, A.; Sula, A.; Wallace, B.A.; Stocks, B.B.; Burns, C.; Cooper-Shepherd, D.; De Lorenzi, E.; Rodriguez, E.; et al. Reference Protocol to Assess Analytical Performance of Higher Order Structural Analysis Measurements: Results from an Interlaboratory Comparison. Anal. Chem. 2021, 93, 9041-9048. [CrossRef]

8. Wang, L.; Chance, M.R. Protein Footprinting Comes of Age: Mass Spectrometry for Biophysical Structure Assessment. Mol. Cell Proteom. 2017, 16, 706-716. [CrossRef] [PubMed]

9. Kaur, U.; Johnson, D.T.; Chea, E.E.; Deredge, D.J.; Espino, J.A.; Jones, L.M. Evolution of Structural Biology through the Lens of Mass Spectrometry. Anal. Chem. 2019, 91, 142-155. [CrossRef] [PubMed]

10. Liu, X.R.; Zhang, M.M.; Gross, M.L. Mass Spectrometry-Based Protein Footprinting for Higher-Order Structure Analysis: Fundamentals and Applications. Chem. Rev. 2020, 120, 4355-4454. [CrossRef]

11. Pan, Y.; Konermann, L. Membrane protein structural insights from chemical labeling and mass spectrometry. Analyst 2010, 135, 1191-1200. [CrossRef] [PubMed]

12. Konermann, L.; Pan, Y.; Stocks, B.B. Protein folding mechanisms studied by pulsed oxidative labeling and mass spectrometry. Curr. Opin. Struct. Biol. 2011, 21, 634-640. [CrossRef] [PubMed]

13. Khanal, A.; Pan, Y.; Brown, L.S.; Konermann, L. Pulsed hydrogen/deuterium exchange mass spectrometry for time-resolved membrane protein folding studies. J. Mass Spectrom. 2012, 47, 1620-1626. [CrossRef] [PubMed]

14. Pan, Y.; Piyadasa, H.; O’Neil, J.D.; Konermann, L. Conformational dynamics of a membrane transport protein probed by H/D exchange and covalent labeling: The glycerol facilitator. J. Mol. Biol. 2012, 416, 400-413. [CrossRef]

15. Pan, Y.; Brown, L.; Konermann, L. Hydrogen exchange mass spectrometry of bacteriorhodopsin reveals light-induced changes in the structural dynamics of a biomolecular machine. J. Am. Chem. Soc. 2011, 133, 20237-20244. [CrossRef]

16. Benesch, J.L.; Ruotolo, B.T. Mass spectrometry: Come of age for structural and dynamical biology. Curr. Opin. Struct. Biol. 2011, 21, 641-649. [CrossRef]

17. Konermann, L.; Pan, J.; Liu, Y.H. Hydrogen exchange mass spectrometry for studying protein structure and dynamics. Chem. Soc. Rev. 2011, 40, 1224-1234. [CrossRef]

18. Karch, K.R.; Coradin, M.; Zandarashvili, L.; Kan, Z.Y.; Gerace, M.; Englander, S.W.; Black, B.E.; Garcia, B.A. Hydrogen-Deuterium Exchange Coupled to Top- and Middle-Down Mass Spectrometry Reveals Histone Tail Dynamics before and after Nucleosome Assembly. Structure 2018, 26, 1651-1663.e1653. [CrossRef]

19. Masson, G.R.; Burke, J.E.; Ahn, N.G.; Anand, G.S.; Borchers, C.; Brier, S.; Bou-Assaf, G.M.; Engen, J.R.; Englander, S.W.; Faber, J.; et al. Recommendations for performing, interpreting and reporting hydrogen deuterium exchange mass spectrometry (HDX-MS) experiments. Nat. Methods 2019, 16, 595-602. [CrossRef] [PubMed]

20. Zheng, J.; Strutzenberg, T.; Pascal, B.D.; Griffin, P.R. Protein dynamics and conformational changes explored by hydrogen/deuterium exchange mass spectrometry. Curr. Opin. Struct. Biol. 2019, 58, 305-313. [CrossRef]

21. Zehl, M.; Rand, K.D.; Jensen, O.N.; Jorgensen, T.J. Electron transfer dissociation facilitates the measurement of deuterium incorporation into selectively labeled peptides with single residue resolution. J. Am. Chem. Soc. 2008, 130, 17453-17459. [CrossRef]

22. Wang, Q.; Borotto, N.B.; Hakansson, K. Gas-Phase Hydrogen/Deuterium Scrambling in Negative-Ion Mode Tandem Mass Spectrometry. J. Am. Soc. Mass Spectrom. 2019, 30, 855-863. [CrossRef] [PubMed]

23. Manzi, L.; Barrow, A.S.; Scott, D.; Layfield, R.; Wright, T.G.; Moses, J.E.; Oldham, N.J. Carbene footprinting accurately maps binding sites in protein-ligand and protein-protein interactions. Nat. Commun. 2016, 7, 13288. [CrossRef] [PubMed]

24. Manzi, L.; Barrow, A.S.; Hopper, J.T.S.; Kaminska, R.; Kleanthous, C.; Robinson, C.V.; Moses, J.E.; Oldham, N.J. Carbene Footprinting Reveals Binding Interfaces of a Multimeric Membrane-Spanning Protein. Angew. Chem. Int. Ed. Engl. 2017, 56, 14873-14877. [CrossRef]

25. Barth, M.; Bender, J.; Kundlacz, T.; Schmidt, C. Evaluation of NHS-Acetate and DEPC labelling for determination of solvent accessible amino acid residues in protein complexes. J. Proteom. 2020, 222, 103793. [CrossRef]

26. Hambly, D.M.; Gross, M.L. Laser flash photolysis of hydrogen peroxide to oxidize protein solvent-accessible residues on the microsecond timescale. J. Am. Soc. Mass Spectrom. 2005, 16, 2057-2063. [CrossRef] [PubMed]

27. Hambly, D.; Gross, M.L. Laser flash photochemical oxidation to locate heme binding and conformational changes in myoglobin. Int. J. Mass Spectrom. 2007, 259, 124-129. [CrossRef]

28. Li, K.S.; Shi, L.; Gross, M.L. Mass Spectrometry-Based Fast Photochemical Oxidation of Proteins (FPOP) for Higher Order Structure Characterization. Acc. Chem. Res. 2018, 51, 736-744. [CrossRef]

29. Vahidi, S.; Konermann, L. Probing the Time Scale of FPOP (Fast Photochemical Oxidation of Proteins): Radical Reactions Extend Over Tens of Milliseconds. J. Am. Soc. Mass Spectrom. 2016, 27, 1156-1164. [CrossRef]

30. Maleknia, S.D.; Brenowitz, M.; Chance, M.R. Millisecond radiolytic modification of peptides by synchrotron X-rays identified by mass spectrometry. Anal. Chem. 1999, 71,3965-3973. [CrossRef]

31. Xu, G.; Chance, M.R. Hydroxyl radical-mediated modification of proteins as probes for structural proteomics. Chem. Rev. 2007, 107, 3514-3543. [CrossRef] [PubMed] 
32. Tullius, T.D.; Dombroski, B.A. Hydroxyl radical "footprinting": High-resolution information about DNA-protein contacts and application to lambda repressor and Cro protein. Proc. Natl. Acad. Sci. USA 1986, 83, 5469-5473. [CrossRef] [PubMed]

33. Jain, S.S.; Tullius, T.D. Footprinting protein-DNA complexes using the hydroxyl radical. Nat. Protoc. 2008, 3, 1092-1100. [CrossRef] [PubMed]

34. Zhu, Y.; Guo, T.; Park, J.E.; Li, X.; Meng, W.; Datta, A.; Bern, M.; Lim, S.K.; Sze, S.K. Elucidating in vivo structural dynamics in integral membrane protein by hydroxyl radical footprinting. Mol. Cell Proteom. 2009, 8, 1999-2010. [CrossRef] [PubMed]

35. Leser, M.; Chapman, J.R.; Khine, M.; Pegan, J.; Law, M.; Makkaoui, M.E.; Ueberheide, B.M.; Brenowitz, M. Chemical Generation of Hydroxyl Radical for Oxidative 'Footprinting'. Protein Pept. Lett. 2019, 26, 61-69. [CrossRef]

36. Johnson, D.T.; Di Stefano, L.H.; Jones, L.M. Fast photochemical oxidation of proteins (FPOP): A powerful mass spectrometry-based structural proteomics tool. J. Biol. Chem. 2019, 294, 11969-11979. [CrossRef]

37. Wang, L.; Chance, M.R. Structural mass spectrometry of proteins using hydroxyl radical based protein footprinting. Anal. Chem. 2011, 83, 7234-7241. [CrossRef]

38. Kolos, J.M.; Voll, A.M.; Bauder, M.; Hausch, F. FKBP Ligands-Where We Are and Where to Go? Front. Pharmacol. 2018, 9 , 1425 [CrossRef]

39. Hahle, A.; Merz, S.; Meyners, C.; Hausch, F. The Many Faces of FKBP51. Biomolecules 2019, 9, 35. [CrossRef]

40. Gaali, S.; Kirschner, A.; Cuboni, S.; Hartmann, J.; Kozany, C.; Balsevich, G.; Namendorf, C.; Fernandez-Vizarra, P.; Sippel, C.; Zannas, A.S.; et al. Selective inhibitors of the FK506-binding protein 51 by induced fit. Nat. Chem. Biol. 2015, 11, 33-37. [CrossRef]

41. Pomplun, S.; Sippel, C.; Hahle, A.; Tay, D.; Shima, K.; Klages, A.; Unal, C.M.; Riess, B.; Toh, H.T.; Hansen, G.; et al. Chemogenomic Profiling of Human and Microbial FK506-Binding Proteins. J. Med. Chem. 2018, 61, 3660-3673. [CrossRef] [PubMed]

42. Pan, J.; Han, J.; Borchers, C.H.; Konermann, L. Hydrogen/deuterium exchange mass spectrometry with top-down electron capture dissociation for characterizing structural transitions of a 17 kDa protein. J. Am. Chem. Soc. 2009, 131, 12801-12808 [CrossRef]

43. Lim, J.; Vachet, R.W. Development of a methodology based on metal-catalyzed oxidation reactions and mass spectrometry to determine the metal binding sites in copper metalloproteins. Anal. Chem. 2003, 75, 1164-1172. [CrossRef]

44. Cox, J.; Mann, M. MaxQuant enables high peptide identification rates, individualized p.p.b.-range mass accuracies and proteomewide protein quantification. Nat. Biotechnol. 2008, 26, 1367-1372. [CrossRef] [PubMed]

45. Tyanova, S.; Temu, T.; Cox, J. The MaxQuant computational platform for mass spectrometry-based shotgun proteomics. Nat. Protoc. 2016, 11, 2301-2319. [CrossRef] [PubMed]

46. Fraczkiewicz, R.; Braun, W. Exact and Efficient Analytical Calculation of the Accessible Surface Areas and Their Gradients for Macromolecules. J. Comp. Chem. 1998, 19, 319-333. [CrossRef]

47. Jagtap, P.K.A.; Asami, S.; Sippel, C.; Kaila, V.R.I.; Hausch, F.; Sattler, M. Selective Inhibitors of FKBP51 Employ Conformational Selection of Dynamic Invisible States. Angew. Chem. Int. Ed. Engl. 2019, 58, 9429-9433. [CrossRef] [PubMed]

48. Parker, B.W.; Goncz, E.J.; Krist, D.T.; Statsyuk, A.V.; Nesvizhskii, A.I.; Weiss, E.L. Mapping low-affinity/high-specificity peptideprotein interactions using ligand-footprinting mass spectrometry. Proc. Natl. Acad. Sci. USA 2019, 116, 21001-21011. [CrossRef]

49. Voll, A.M.; Meyners, C.; Taubert, M.C.; Bajaj, T.; Heymann, T.; Merz, S.; Charalampidou, A.; Kolos, J.; Purder, P.L.; Geiger, T.M.; et al. Macrocyclic FKBP51 Ligands Define a Transient Binding Mode with Enhanced Selectivity. Angew. Chem. Int. Ed. Engl. 2021, 60, 13257-13263. [CrossRef]

50. Schopper, S.; Kahraman, A.; Leuenberger, P.; Feng, Y.; Piazza, I.; Muller, O.; Boersema, P.J.; Picotti, P. Measuring protein structural changes on a proteome-wide scale using limited proteolysis-coupled mass spectrometry. Nat. Protoc. 2017, 12, 2391-2410. [CrossRef]

51. Leuenberger, P.; Ganscha, S.; Kahraman, A.; Cappelletti, V.; Boersema, P.J.; von Mering, C.; Claassen, M.; Picotti, P. Cell-wide analysis of protein thermal unfolding reveals determinants of thermostability. Science 2017, 355, eaai7825. [CrossRef]

52. Wilson, K.P.; Yamashita, M.M.; Sintchak, M.D.; Rotstein, S.H.; Murcko, M.A.; Boger, J.; Thomson, J.A.; Fitzgibbon, M.J.; Black, J.R.; Navia, M.A. Comparative X-ray structures of the major binding protein for the immunosuppressant FK506 (tacrolimus) in unliganded form and in complex with FK506 and rapamycin. Acta Crystallogr. D Biol. Crystallogr. 1995, 51, 511-521. [CrossRef] [PubMed]

53. Gaali, S.; Feng, X.; Hahle, A.; Sippel, C.; Bracher, A.; Hausch, F. Rapid, Structure-Based Exploration of Pipecolic Acid Amides as Novel Selective Antagonists of the FK506-Binding Protein 51. J. Med. Chem. 2016, 59, 2410-2422. [CrossRef]

54. Bauder, M.; Meyners, C.; Purder, P.L.; Merz, S.; Sugiarto, W.O.; Voll, A.M.; Heymann, T.; Hausch, F. Structure-Based Design of High-Affinity Macrocyclic FKBP51 Inhibitors. J. Med. Chem. 2021, 64, 3320-3349. [CrossRef] [PubMed]

55. Resetca, D.; Wilson, D.J. Characterizing rapid, activity-linked conformational transitions in proteins via sub-second hydrogen deuterium exchange mass spectrometry. FEBS J. 2013, 280, 5616-5625. [CrossRef]

56. Deng, B.; Zhu, S.; Macklin, A.M.; Xu, J.; Lento, C.; Sljoka, A.; Wilson, D.J. Suppressing allostery in epitope mapping experiments using millisecond hydrogen/deuterium exchange mass spectrometry. MAbs 2017, 9, 1327-1336. [CrossRef]

57. Bellamy-Carter, J.; Oldham, N.J. PepFoot: A Software Package for Semiautomated Processing of Protein Footprinting Data. J. Proteome Res. 2019, 18, 2925-2930. [CrossRef] [PubMed]

58. Kozany, C.; Marz, A.; Kress, C.; Hausch, F. Fluorescent probes to characterise FK506-binding proteins. Chembiochem 2009, 10, 1402-1410. [CrossRef] 
59. Bracher, A.; Kozany, C.; Thost, A.K.; Hausch, F. Structural characterization of the PPIase domain of FKBP51, a cochaperone of human Hsp90. Acta Crystallogr. D Biol. Crystallogr. 2011, 67, 549-559. [CrossRef] [PubMed]

60. Marty, M.T.; Baldwin, A.J.; Marklund, E.G.; Hochberg, G.K.; Benesch, J.L.; Robinson, C.V. Bayesian deconvolution of mass and ion mobility spectra: From binary interactions to polydisperse ensembles. Anal. Chem. 2015, 87, 4370-4376. [CrossRef] 